\title{
A Two-Wave Assessment of the Structure and Stability of Self-Reported Problematic Pornography Use Among Male Croatian Adolescents
}

Štulhofer, Aleksandar; Rousseau, Ann; Shekarchi, Rezvan

Source / Izvornik: International Journal of Sexual Health, 2020, -, 1 - 14

Journal article, Accepted version

Rad u časopisu, Završna verzija rukopisa prihvaćena za objavljivanje (postprint)

https://doi.org/10.1080/19317611.2020.1765940

Permanent link / Trajna poveznica: https://urn.nsk.hr/urn:nbn:hr:131:530381

Rights / Prava: In copyright/Zaštićeno autorskim pravom.

Download date / Datum preuzimanja: 2023-04-26

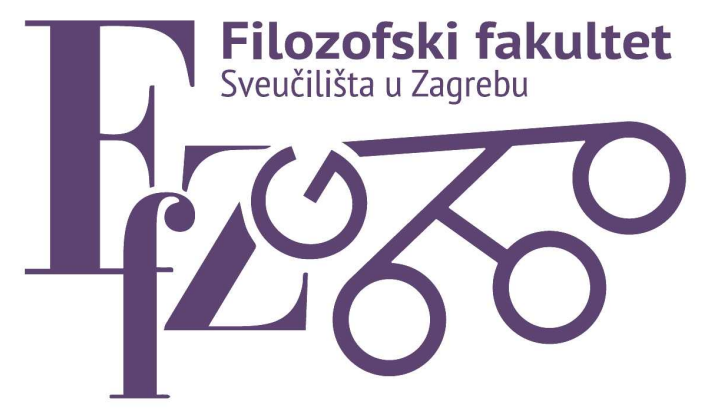

\section{Repository / Repozitorij:}

ODRAZ - open repository of the University of Zagreb Faculty of Humanities and Social Sciences
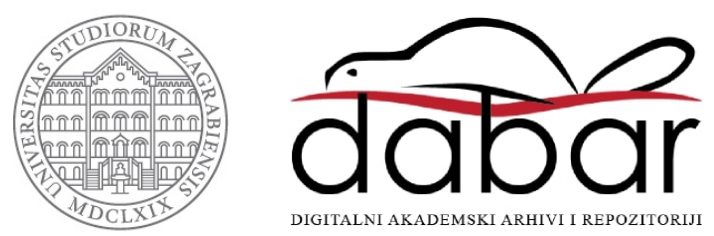


\title{
A Two-Wave Assessment of the Structure and Stability of Self-Reported Problematic Pornography Use Among Male Croatian Adolescents
}

\author{
Aleksandar Štulhofer, PhD \\ Department of Sociology, Faculty of Humanities and Social Sciences, University of Zagreb, \\ Zagreb, Croatia \\ Ann Rousseau, $\mathrm{PhD}$ \\ School for Mass Communication Research, KU Leuven, Belgium \\ Rezvan Shekarchi \\ Department of Psychology, University of Padova, Italy
}

Running Head: Structure of Adolescents' Problematic Pornography Use

\section{Address for Correspondence:}

Aleksandar Štulhofer, PhD

Dept. of Sociology, Faculty of Humanities and Social Sciences, University of Zagreb

I. Lučića, 3, 10000 Zagreb, Croatia

E-mail: astulhof@ffzg.hr

\section{Acknowledgement:}

The study was funded by the Croatian Science Foundation (grant no. 922 awarded to A. Štulhofer). A. Rousseau was supported by a postdoctoral fellowship from the Flemish Fund for Scientific Research (FWO). 


\begin{abstract}
:
Objectives: In spite of growing concerns about adolescents' pornography use, research on problematic pornography use (PPU) in this population is scarce.

Method: We examined the structure and prevalence of PPU symptoms across six months in 337 male Croatian adolescents.

Results: Network analysis indicated that associations among PPU symptoms were highly stable, which was not the case with being at risk for PPU. Less than 5\% of the panel participants appeared to be at risk for PPU.

Conclusions: This study's findings may help increase awareness and reduce moral panic about PPU among parents and teachers, and inform emerging pornography literacy programs.
\end{abstract}

Key Words: Pornography, problematic use, adolescents, network analysis 


\section{A Two-Wave Assessment of the Structure and Stability of Self-Reported Problematic Pornography Use Among Male Croatian Adolescents}

\section{INTRODUCTION}

Pornography has become readily available due to advanced digital technologies and broad internet access (Griffiths, 2012). Already in 1998, Cooper proposed that the rising popularity of online pornography reflected its unprecedented access, affordability and anonymity (Cooper, 1998). Increasing use of pornography has been observed not only among adults but also among young people, including adolescents (Grubbs, Kraus, \& Perry, 2019; Peter \& Valkenburg, 2016). Although pornography has been associated with some benefits, such as sexual pleasure and selfeducation (Böthe, Vaillancourt-Morel, Bergeron, \& Demetrovics, 2019), it can also be problematic - i.e., related to adverse outcomes, such as sexual risk taking, dominance of recreational attitudes toward sex, or sexual callousness (Bőthe, Tóth-Király, Demetrovics, \& Orosz, 2017; Peter \& Valkenburg, 2016).

To distinguish between problematic and non-problematic pornography use (Sniewski, Farvid, \& Carter, 2018), Kor et al. (2014) proposed four defining characteristics of problematic pornography use (PPU): (a) extremely frequent, excessive use; (b) use motivated by a desire to supress negative mood; (c) reduced self-control over pornography use; and (d) continued use despite negative consequences in other life domains. In contrast to research on problematic pornography use among adults, studies among adolescents are sparse — in spite of growing societal concerns about pornography use among adolescents (Keen, France, \& Kramer, 2019). Given this lack of explorations into adolescent PPU, the objectives of the current study are primarily exploratory. We aim to: (1) address associations between adolescents' PPU and life and 
sexual satisfaction, (2) assess the structure of the network of ties among PPU symptoms, and (3) identify the proportion of male adolescents at risk for PPU.

\section{Conceptualizations of PPU}

Currently, there is no consensus about how PPU should be conceptualized (Fernandez \& Griffiths, 2019; Wery \& Billieux, 2017). In the context of considerations about the structure of PPU, a couple of conceptualizations are of particular interest. The first is a multi-component model based on a biopsychosocial addiction framework, that was proposed by Griffiths (2005) and applied to PPU by Böthe et al. (2018). The model includes salience, which refers to an extreme personal importance of pornography and its impact on thoughts, feelings, and behaviors, mood modification, or efforts to alleviate negative mood by pornography use, conflict, defined as distress caused by friction between pornography use and other facets of life (e.g., partnership or professional commitments), tolerance, which refers to an increasing frequency of use needed to achieve the same psychological effects, relapse, or the tendency to fall back to the previous pattern of use after a period of abstinence, and withdrawal, defined as unpleasant feelings and emotions that accompany abstaining from pornography use. Another, more recent, model was developed using a compulsive use framework (Noor, Rosser, \& Erickson, 2014a). Following the DSM-5 definition of obsessive-compulsive disorder, the authors conceptualized PPU as a latent construct defined by five specific components: salience, control, mood modification, distress, and negative effect on sexual life as specific domains. Exploratory factor analysis of their brief PPU measure revealed two latent dimensions - intrusive thoughts about (obsessive facet) and perceived lack of control over pornography use (compulsive facet) (Noor et al., 2014a).

In their recent overview of measures used to assess PPU, Fernandez and Griffiths (2019) found that the following four components were most frequently assessed in the 22 reviewed PPU measures: impaired control, salience, mood modification, and conflict. 


\section{Prevalence of PPU in Adults}

In the developed world, pornography use is a common behaviour, with studies reporting that up to $70 \%$ of men and $40 \%$ of women in the U.S.A. (Regnerus, Gordon, \& Price, 2016), and $76 \%$ of men and $41 \%$ of women in Australia (Rissel et al., 2017) used pornography in the past year. According to the literature, only a minority of users may be at risk for PPU. For example, in the Rissel et al. (2017) study, 4\% of male and 1\% of female participants reported that they felt addicted to pornography. Interestingly, only about half of these self-labelled participants claimed that pornography use has negatively affected their life. In another recent study of 2,075 adults, proportions of participants with self-reported addiction to pornography were somewhat higher (11\% of male and 3\% of female individuals) (Grubbs, Kraus, \& Perry, 2019).

In a sample of 830 North American adults who completed an online survey about cybersex, $11.8 \%$ of participants were categorized as compulsive pornography users (Vaillancourt-Morel et al., 2016). These individuals had lower sexual satisfaction and higher rates of sexual dysfunction than other study participants. The authors also reported that $12.7 \%$ of participants who were not characterized as compulsive users were highly distressed about their pornography use. Comparably, a recent German study that included 1,498 heterosexual men found that $15 \%$ of participants reported unregulated online pornography use (Anton et al., 2019). Compared to other participants, these men showed the highest craving for sexually explicit material, impulsivity, dysfunctional coping, and delay discounting scores.

\section{Pornography Use and PPU in Adolescents}

Pornography use in adolescence is often viewed as particularly concerning due to a combination of increasing sexual interest, high internet use, and the specifics of adolescent brain development (e.g., higher impulsivity and greater reward sensitivity; see Laili, Puspitawati, \& 
Yuliati, 2018; Owens, Behun, Manning, \& Reid, 2012). Compared to adults, these factors may make young people more vulnerable to adverse effects of pornography use. Findings on the prevalence of pornography use among adolescents differ greatly due to differences in defining pornography, sampling approaches, and other methodological problems (Kohut, 2014). It has been estimated that approximately $7-59 \%$ of adolescents intentionally use pornography (Peter \& Valkenburg, 2016). To date, most studies have been carried out on problematic pornography use in adults or emerging adults. We were able to find only five studies of relevance for the phenomenon of PPU among adolescents. In a study conducted in a sample of 618 Israeli highschool students aged $14-18$ years, $14 \%$ of participants were classified, using latent profile analysis, in a compulsive sexual behavior group (Efrati \& Gola, 2018). Participants in this group reported a substantially higher frequency of pornography use than their peers. In another study, carried out in two samples of adolescents and emerging adults from Spain and Mexico $(n=1,189$ and $n=1,038$, respectively), the proportion of adolescents who were at risk for compulsive, out of control online sexual behavior was, overall, about one percent (Ballester-Arnal, Gil-Llario, Giménez-García, Castro-Calvo, \& Cardenas-López, 2017). In contrast to young adults, the membership in this at risk group was not significantly associated with pornography use among adolescents. Another study, carried out among 1,902 Swedish male adolescents aged 18 years, found that $10.5 \%$ of participants used pornography on a daily basis (Svedin, Akerman, \& Priebe, 2011). Compared to other participants, the high frequency users were characterized by substantially higher sexual interest and alcohol consumption. In a sample of 1,492 senior Italian high-school students, Pizzol, Bertoldo, and Foresta (2016) found that $10 \%$ of participants who used pornography also reported reduced interest in partnered sex, while $9.1 \%$ reported "a kind of addiction". Finally, Kohut and Štulhofer (2018b) explored a link between religiosity and compulsive pornography use in two longitudinal panels of male Croatian adolescents. According 
to their findings, symptoms of compulsive pornography use were significantly related to both baseline levels and subsequent growth in the frequency of pornography use between middle and late adolescence. Interestingly, growth in pornography use among adolescents high in compulsivity was observed primarily among more religious participants.

\section{Current Study}

Given the paucity of studies exploring PPU in adolescence, and particularly the absence of insights into the structure of PPU symptoms, the aim of the current study is primarily exploratory. We focused on male adolescents primarily for two reasons. First, there is consistent evidence that problematic pornography use is substantially more prevalent among men than women (Mitchell \& Wells, 2007; Rissel et al., 2017; Ross, Månsson, \& Daneback, 2012). This is consistent with large gender differences in the use (and frequency) of pornography use (Hald, 2006; Kvalem, Træen, Lewin, \& Štulhofer, 2014; Rissel et al., 2017), as well as with more prevalent habitual use of pornography among male participants, compared to their female peers (Paul \& Shim, 2008). Second, research literature also points to marked differences in the use of pornography use in male vs. female adolescents (see Doornwaard, van den Eijnden, Overbeek, \& ter Bogt, 2015; Lo \& Wei, 2005; Peter \& Valkenburg, 2016). The difference was recently corroborated in another paper from this research project (Tomić, Burić, \& Štulhofer, 2018).”

Our assessment is organized around the following three research questions:

RQ1 - Is adolescent PPU negatively associated with sexual and life satisfaction, as has been observed among adults and emerging adults (Harper \& Hodgins, 2016; Kraus et al., 2018)?

RQ2 - What is the pattern of interrelationships among different facets of PPU (i.e., the structure of ties between PPU symptoms) and how stable is it over time?

RQ3 - How many male adolescents in this study may be characterized as at risk for PPU and how consistent is the risk over a period of six months? 
Two of the three research questions have clear clinical implications. The RQ2 taps into clinical relevance of adolescent PPU (the more stable the pattern of symptoms, the more relevant the underlying psychological construct) and informs targeted interventions by identifying symptoms that occupy central positions in the network of PPU symptoms. The RQ3 focuses on the stability of experiencing PPU, which is essential for the assessment of prevalence of PPU in male adolescents, but also important to avoid psychopathologization of developmentally-specific sexual exploration. Moral panic about young people's pornography use is hardly a favorable social climate for providing adequate help to adolescents who really need it.

\section{METHOD}

\section{Participants and Procedure}

In this study, we use data from a larger study (PROBIOPS: Prospective Biopsychosocial Study of the Effects of Sexually Explicit Material on Young People's Sexual Socialization and Health; ***blinded for review***) that focused on adolescents' use of sexualized media. In December 2015, we recruited 1,287 high-school sophomore students of both gender $(M=15.9$ years, $S D=0.52$ ) from 14 larger secondary schools in the third largest Croatian city (the selected schools included more than $60 \%$ of the respective population). Panelists were re-surveyed five times at approximately 5-month intervals. Surveying was carried out in classrooms, with screens placed between participants to maximize confidentiality. The panel size dropped to 892 at the final study wave (T6), primarily because students who were enrolled in 3-year vocational schools finished their secondary education prior to T5. Remaining attrition was related to school absenteeism and, to a lesser extent, errors in re-creating a simple 5-digit alphanumeric identification code used to link responses.

Due to the fact that PPU was only measured at T5 and T6, the current study uses data from 337 male adolescents $\left(M_{\text {age at baseline }}=15.8, S D=0.48\right)$ who participated in the final study 
wave. A multivariate logistic regression analysis was carried out to address possible bias introduced by selective attrition. Dependent variable was participation at T6 $(0=$ those who did not participate in T6 $(n=406)$ and $1=$ those who participated in T6 $(n=337))$; independent variables were age, mother's and father's education, academic achievement, the experience of sexual intercourse, and pornography use at baseline. Male adolescents who were included in this study were younger $(\mathrm{AOR}=0.54, p=.003)$, had somewhat better grades $(\mathrm{AOR}=1.53, p=.011)$, and had lower odds of reporting sexual intercourse at $\mathrm{T} 1(\mathrm{AOR}=0.52, p=.005)$ than other participants.

Following national guidelines for research in minors (Kolesarić \& Ajduković, 2003), prospective participants' parents were sent information about the study prior to surveying. Consent-related information for participants was printed on the first page of all study questionnaires, but was also explained in detail (in the classroom, at each data collection wave) by a research assistant. The questionnaires also contained the contact of a national organization that offers support and counseling to children and young people. The Ethical Research Board of the University of (*** blinded for review $* * *)$ approved all study procedures.

\section{Measures}

To enable longitudinal assessment of a wide range of beliefs, attitudes, and behaviors relevant for an exploration of the use of sexualized media in adolescence, indicators used in the PROBIOPS questionnaires were reasonably brief.

Frequency of pornography use was measured at each wave (T1 - T6) with the following item: How often have you used pornography during the last 6 months? Answers were documented using an 8 -point scale $(1=$ not once, $2=$ several times, $3=$ once a month, $4=2-3$ times a month, $5=$ once a week, $6=$ several times a week, 7 = every day or almost every day, and $8=$ several times a day). Pornography was defined as any material which openly (i.e., not 
censored) depicts sexual activity; material which shows naked bodies but not sexual intercourse or other sexual activity does not belong to pornography as here defined. The indicator has solid test retest reliability, with stability coefficients in the .78 (T1-T2) to .50 (T1-T6) range.

Problematic pornography use, which was assessed only in male participants, was measured at T5 and T6 by the 5-item Compulsive Pornography Consumption scale (Noor, Rosser, \& Erickson, 2014b). Due to the fact that the scale was developed in two samples of gay men, the measure was pre-tested in a sample of 167 male Croatian adolescents from the capital city and found internally consistent (McDonald's $\omega=.78$ ). The items tapped into intrusiveness of pornography use (I thought of pornography when I was trying to focus on other things), related lack of control (I was upset because I could not stop thinking about pornography), compulsive use (I watched pornography even though I did not want to), using pornography for mood modification (It was necessary for me to watch pornography to feel at ease), and sexual difficulties associated with the use of pornography (I could only have an orgasm when watching pornography). A 5-point scale (1= never, $5=$ always $)$ was used to anchor answers. The measure had moderate stability over a 6 -month period $(r=.48)$ and acceptable internal consistence at both T5 and T6 (McDonald's $\omega=.80$ and .75).

Sexual Satisfaction was measured at T5 and T6 with the following question: In general, how satisfied are you with your sex life? The question was asked to all participants, regardless of their sexual experience. A 7-point scale ranging from $1=$ completely unsatisfied to $7=$ completely satisfied was used to anchor answers. The indicator has satisfactory stability in the observed period $(r=.51)$.

Life Satisfaction was assessed at T6 by an adapted 5-item version of the Personal Wellbeing Index-School Children (PWI-SC; Tomyn \& Cummins, 2011). The items indicated the level of satisfaction with one's health, life achievements, important relationships, perceived 
future, and life in general. Answers were recorded on a Likert-like scale ( $1=$ extremely dissatisfied, 5 = extremely satisfied), with an exception of the item How do you see your future that ranged from $1=$ very negative to $5=$ very positive. The scores were averaged to form a composite scale (Cronbach's $\alpha=.81$ ).

\section{Statistical Analysis}

The percentage of missing values on key variables (PPU, sexual and life satisfaction) at T6 was $<3 \%$, with Little's test $\left(\chi^{2}(7)=10.96, p=.141\right)$ suggesting that data were missing completely at random. Three analytical approaches were used in the current study: linear mixed effects regression modeling (LMMRM), psychometric network analysis, and latent profile analysis. The first method enabled flexible and robust analysis of repeatedly measured constructs, while controlling for clustering effects which are typical in classroom-based surveying (Hox, 2010; Peugh, 2010). Psychometric network analysis, which has been extensively used to explore the structure of a range of psychological and psychopathological constructs (Cramer \& Borsboom, 2015; Fried et al., 2017; Werner, Štulhofer, Waldorp, \& Jurin, 2018), was employed to assess the stability of associations among symptoms in the PPU network at T5 and T6, as well as links between the frequency of pornography use and PPU symptoms. In such network analysis, symptoms of a specific psychological problem constitute nodes, while their interactions or tiesoperationalized as partial correlations_-represent network edges (Borsboom, 2008). Compared to standard statistical approaches, network analysis enables a detailed insight into the structure of symptoms, including the identification of core or centrally positioned symptoms, which may have high clinical relevance (Borsboom, 2017; Cramer \& Borsboom, 2015). Finally, to avoid arbitrary criteria and cutoff points, we used latent profile analysis to establish the proportion of participants who are at risk for PPU. The approach has several benefits over somewhat more common clustering techniques, including probabilistic grouping of individuals (characterized by a similar 
pattern of values on a selected indicator) into distinct underlying profiles and identifying the optimal number of these latent groups based on model fit (Jung \& Wickrama, 2008; Oberski, 2016; Williams \& Kibowski, 2016). Following recommendations in the literature, we tested models with one to four profiles and evaluated them by observing change in AIC, BIC, sampleadjusted BIC, and entropy scores. Interpretability and size of the smallest group $(>5 \%$ of participants) were additional criteria.

The analyses were carried out using jamovi (descriptive and LMMRM analyses; the jamovi project, 2019), JASP (descriptive network analysis; JASP Team, 2019), R (Version 3.5.2.) with NetworkComparisonTest package (Van Borkulo et al., 2016), and MPlus 8.1 (latent profile analysis; Muthén \& Muthén, 2017) statistical software packages.

\section{RESULTS}

Most participants (80.3\%) were living with both parents at baseline. Only ten participants reported a parent with only primary education. Of the rest, a half (50.2\%) reported collegeeducated mother and $41.9 \%$ college-educated father. In comparison, the population proportion of tertiary educated individuals of the corresponding age is $<20 \%$ (Croatian Bureau of Statistics, 2019). Religiosity levels were low in the panel. At baseline, $16.1 \%$ of participants attended religious ceremonies several times a month or more often, $12.7 \%$ attended them once in several years, while $21.3 \%$ reported that they never attend religious ceremonies. A minority of panelists $(16.1 \%)$ reported sexual intercourse at the initial study wave.

\section{RQ1: Sexual and Life Satisfaction as Predictors of Adolescent PPU}

In an unconditional model with 63 classrooms (from 14 high-schools) as random effect, data clustering in classes accounted for $9 \%$ of variance in PPU over time. In the next step, sexual and life satisfaction were included as fixed effect predictors. As shown in Table 1, both indicators were significantly associated with the outcome. Change in sexual satisfaction between T5 and T6 
was negatively associated with change in PPU in the same period $(b=-.18, p=0.041)$. The relationship between change in PPU and life satisfaction at T6 was also negative $(b=-.12, p=$ 0.008). However, after participants' age was controlled for (see Table 1), only life satisfaction remained significantly associated with the outcome $(b=-.14, p=0.006)$.

$$
\text { *** TABLE } 1 \text { ABOUT HERE *** }
$$

\section{RQ2: The Structure of Adolescent PPU and Its Stability}

The structure of PPU network at T5 and T6 is presented in Figure 1. Both undirected networks, which represent conditional associations (i.e., regularized partial correlations) among symptoms, were estimated by Gaussian graphical model and graphical LASSO estimator, based on extended BIC model selection (Epskamp, Borsboom, \& Fried, 2018). To provide more parsimonious and stable network solution, the estimator 'regularizes' networks by shrinking weak edges to zero. The two PPU networks were visualized using the circle layout. Considering data dependence due to repeated observations, the PPU network at T6 was represented by difference scores obtained by subtracting T5 items from their T6 pair.

There were some observable differences between the T5 and T6 PPU networks, both in density (the number of non-zero edges was $7 / 10$ at $\mathrm{T} 5$ and $9 / 10$ at T6) and edge strength (mean strength was $0.20, S D=0.18$, at T5 and $0.16, S D=0.12$, at T6). In the next step, we used the network comparison test (NCT; Van Borkulo et al., 2016) to establish whether the two networks substantially differed. Three separate assessments are included in the NCT: (a) a test of network structure invariance (permutation-based maximum difference between edge strength matrices), a test of global connectivity invariance (permutation-based test of a difference between absolute sum of all edges in two networks), and a test of edge strength invariance, which is relevant only if network structure is significantly different between the two groups or time points (Van Borkulo et al., 2016). Given that the NCT can be specified to analyze dependent data, we used original T6 
items (not the difference scores) for the analysis. According to the findings, both the PPU network structure $(M=0.12, p=.976)$ and its global connectivity $(\mathrm{S}=0.116, p=0.891)$ were invariant over time.

Taking into account that the more centrally an edge is positioned, the higher its importance or influence (i.e., connectivity), we also explored centrality of the five PPU at two time points. As shown in Figure 2, The item reflecting a lack of control over pornography use ( was upset because I could not stop thinking about pornography) had the highest degree or strength centrality — which is defined as the sum of its edges — at T5, but not T6. The highest strength at T6 was observed for the compulsive use item (I watched pornography even though I did not want to). In the case of betweenness and closeness centrality, the two indices based on the concept of shortest path (Hevey, 2018), no differences were observed between T5 and T6 networks. The lack of control and compulsive use items shared the highest betweenness, while the compulsive use item was characterized by the highest closeness.

\section{*** FIGURES 1 AND 2 ABOUT HERE ***}

\section{RQ3: Adolescents at Risk for PPU}

How many participants in our panel sample were at risk for PPU? This is a particularly sensitive issue in middle to late adolescence, the period marked by increasing pornography use (Willoughby, Young-Petersen, \& Leonhardt, 2018) and, for many, intense sexual explorations and experimentation. In the absence of established and clinically validated cutoff points, the answer to the question appears unavoidably arbitrary. To minimize arbitrariness, we employed latent profile analysis, separately for T5 and T6 to enable the exploration of stability of classification over time. At both time points, the model with two latent classes (low and high PPU) was identified as optimal based on the largest drop in AIC, BIC and SABIC values, entropy, and interpretability (see Table 2). Of the 262 male adolescents who took part in both 
study waves, membership in the high PPU latent profile was established for $12.1 \%$ at $\mathrm{T} 5$ and $11.6 \%$ at $\mathrm{T} 6$.

Consistency of being classified in the high PPU profile group was explored by analyzing the overlap between the membership in T5 and T6. Of the 50 male adolescents who were classified in the high PPU profile at either T5 or T6, 12 belonged to this group in both study waves. Considering the developmental character of adolescent sexuality, we find these 12 adolescents ( $4.6 \%$ of the panel sample) to be at risk for PPU.

\section{DISCUSSION}

Prompted by concerns about the use of pornography in young people, which include fears that immersion in pornographic imagery of impersonal sex and hypersexualized bodies may be linked to adverse psychological health outcomes in young users (Kohut \& Štulhofer, 2018a), we sought to examine the structure of and risk for PPU in male Croatian adolescents. Using longitudinal data, we tested the following research questions: (1) what is the association between sexual and life satisfaction and PPU; (2) what is the structure of adolescent PPU and how stable is it; (3) how many adolescents are at risk for PPU? According to the findings, reported PPU symptoms were significantly and negatively linked to participants' life satisfaction. Although the two most centrally positioned symptoms in the PPU network changed positions from T5 to T6, the structure of PPU symptoms remained stable in the 6-month period. This stability, however, was not matched by consistency in experiencing PPU symptoms. While about $12 \%$ of panelists reported PPU symptoms at either data collection wave, less than five percent reported the symptoms at both study waves — reflecting a substantial "fluidity" of adolescent PPU. More research is needed to understand possible sources of such fluidity, which are unclear at the moment. Due to the fact that, on average, our participants were characterized by a slight nonlinear growth in pornography use across time (see Štulhofer, Tafro, \& Kohut, 2019), the 
observed fluidity may indicate changes in feelings about one's pornography use, perhaps due to entering a romantic relationship, or a more general moral ambivalence. The latter might correspond with increasing levels of religiosity among young people in the country (Marinović Jerolimov \& Jokić, 2010).

In the current study, participants with higher PPU scores had lower life satisfaction compared to their peers who were characterized by lower PPU scores. This is an expected finding given the distress and compulsiveness echoing through PPU symptoms. Interestingly, sexual satisfaction had no independent relationship with PPU, which may be related to participants' age and restricted sexual experience. Taking into account that pornography use among LGBTQ adolescents is often an essential source of developing sexual identity and learning about nonheterosexual erotic activities (Bőthe et al., 2019), the question remains whether sexual identity can moderate the association between PPU and life satisfaction and well-being in general. An answer may depend on the relationship between the frequency of pornography use and (selfassessed) PPU, and LGBTQ adolescents might be less likely to take a frequent pornography use as the sign of an "addiction" or sexual compulsivity.

Given the lack of studies on adolescent PPU, we were unable to find other reports about the links between PPU and life and sexual satisfaction in adolescence. In contrast to our observation, several studies carried out in adult samples reported a significant and negative association between PPU and sexual satisfaction (Bothe et al., 2017; Szymanski \& StewartRichardson, 2014; Vaillancourt-Morel et al., 2016). Taking into account that frequent pornography use may be a substitution for unsatisfying partnered sex but also an obstacle for satisfying partnered sex, the difference between our finding of no association between PPU and sexual satisfaction and the negative relationships reported in adult samples may reflect the fact 
that middle to late male adolescents are substantially less likely to be in a committed romantic relationship than adult men.

Following the network analytic approach that was recently employed in the context of adult hypersexuality (Werner et al., 2018), we explored the structure of PPU symptoms and its stability in the 6-month period. This enabled some novel insights. First, we observed no significant differences in the pattern of associations among the five PPU symptoms across time. According to the centrality estimates, watching pornography in spite of not wanting it and being upset for not being able to stop thinking about pornography constitute the core of PPU symptoms in adolescence. The fact that distress about pornography use appeared to be primarily generated by unwanted intrusive thoughts rather than actual experience of negative consequences may be developmentally-specific (compared to adolescents, adults have more numerous and more complex social roles). ${ }^{1}$ In addition, these centrally positioned symptoms — as has been postulated within the clinical network approach community (Cramer \& Borsboom, 2015; Nuijten, Deserno, Cramer, \& Borsboom, 2016) — are likely of heightened importance for clinical practice. The recently evaluated Acceptance and Commitment Therapy (ACT) (Crosby \& Twohig, 2016) appears to be a promising clinical approach to helping adolescents struggling with PPU. The fact that the ACT targets a number of processes (acceptance, defusing, self-contextualization, presence, committed action, and psychological flexibility; see Hayes, Luoma, Bond, Masuda, \& Lillis, 2006)) that have been linked to reduced effects of unwanted "inner experiences on overt behavior" (Twohig \& Crosby, 2010), including adults PPU (Crosby \& Twohig, 2016), seems well-suited for tackling the core symptoms of PPU observed in the current study.

\footnotetext{
${ }^{1}$ It should be noted that the finding may also explain the absence of a significant relationship between sexual satisfaction and PPU in our sample.
} 
As noted in the introduction, there has been little systematic effort to assess the prevalence of the PPU in adolescents. The proportion of male adolescents in the current study who were found at risk for PPU is in keeping with the available international evidence (Efrati \& Gola, 2018; Pizzol et al., 2016; Svedin et al., 2011). The comparison, however, should be considered with caution, because the Italian, Israeli, Swedish and Croatian studies differed in conceptualization and measuring of PPU, but also in analytical approaches used to estimate the size of the group of interest. In contrast to the other three studies, we measured PPU at two time points, which enabled exploring the stability of PPU symptoms, as well as the consistency of experiencing them. The later assessment indicated that any attempts to diagnose PPU in late adolescence would be highly problematic. This, however, does not negate that a minority of adolescents may experience problems related to their pornography use that require counselling or other forms of psychological health assistance. It should be noted that the assistance would not be necessarily needed for any underlying psychopathology, but to deal with the effects of internalized values and beliefs that are incompatible with pornography use. For example, to use pornography would be norm violating for highly religious adolescents, as well as those who espouse feminist anti-porn value perspective.

\section{Study Strengths and Limitations}

To the best of our knowledge, the current study provides first insights into the structure of PPU among male adolescents. In addition, the repeated measurement approach enabled the exploration of stability of this network of symptoms, as well as the stability of experiencing PPU. Apart from these strengths, the current study is also characterized by a few limitations. The first is related to the observed attrition bias, as older and more sexually experienced participants were more likely to be lost for follow-up. Although it remains unclear to what extent PPU may be related to male adolescents' sexual experience, it is possible that the observed bias affected the 
prevalence of PPU in our panel sample. Next, the stability of network estimations, particularly the estimation of betweenness and closeness centrality — which has been shown to be highly sensitive to statistical power (Epskamp et al., 2018) - is limited in the current study. Although its restricted power did not affect edge estimation, smaller differences in centrality ranking should be considered with caution. Finally, it remains unclear to what extent our findings may be culture-specific, which is particularly relevant when thinking about the here reported prevalence and experiential stability of adolescent PPU.

\section{CONCLUSIONS AND FUTURE DIRECTIONS}

Given the substantial prevalence of pornography use among young people, distressing and problematic use among adolescents has received surprisingly little attention. In part, this may reflect expected or perceived difficulties in obtaining ethical approval for studies that focus on adolescent pornography use, but also a lack of consensus on how to conceptualize and measure PPU. Pointing to the stability of its structure, the current study suggests that PPU is an empirical phenomenon linked to lower life satisfaction in male adolescents. The reader should be reminded, though, that a great majority of participants did not report PPU and that their pornography useas reported in another study from the PROBIOPS research project (Štulhofer et al., 2019) — does not appear to be associated with reduced well-being.

Our findings also indicate that PPU—when assessed as a stable experiential characteristic - is very rare in this population, which is compatible with developmental dynamics and emotional challenges experienced in that age. Taken together, these insights call for future research in several directions. Firstly, more detailed assessment of PPU, with particular emphasis on mechanism underlying the association between pornography consumption and PPU, is needed in both male and female, as well as among heterosexual and non-heterosexual, adolescents. Considering the dynamics of adolescent development, longitudinal designs should be strongly 
prioritized over cross-sectional. Secondly, we need more evidence about the validity of different measurement approaches to adolescent PPU. Currently, there is a lack of information about the validity of measures developed and validated in adult samples when applied to adolescents. Are there differences in the structure of PPU symptoms in adults vs. adolescents? Thirdly, more focus on clinically-relevant characteristics is needed: Is adolescent PPU mostly due to moral incongruence (Grubbs \& Perry, 2019; Kohut \& Štulhofer, 2018b); does it frequently represent a relatively short-lasting developmental phase related to the "discovery" of sexually explicit material; which symptoms should counseling for adolescent PPU target first?

The results of the current study can help increase awareness and reduce moral panic among parents and teachers about risks associated with excessive pornography use. They may also inform future pornography literacy programs (Dawson, Nic Gabhainn, \& MacNeela, 2019; Vandenbosch \& van Oosten, 2017). In the clinical context, youth health experts might use our insights in the assessment of risks associated with frequent male adolescents' pornography use and the need for counseling. 


\section{REFERENCES}

Ballester-Arnal, R., Gil-Llario, M. D., Giménez-García, C., Castro-Calvo, J., \& Cardenas-López, G. (2017). Sexuality in the Internet Era: Expressions of Hispanic Adolescent and Young People. Sexual Addiction \& Compulsivity, 24(3), 140-155.

https://doi.org/10.1080/10720162.2017.1329041

Borsboom, D. (2008). Psychometric perspectives on diagnostic systems. Journal of Clinical Psychology, 64(9), 1089-1108. https://doi.org/10.1002/jclp.20503

Borsboom, D. (2017). A network theory of mental disorders. World Psychiatry, 16(1), 5-13. https://doi.org/10.1002/wps.20375

Bőthe, B., Tóth-Király, I., Demetrovics, Z., \& Orosz, G. (2017). The pervasive role of sex mindset: Beliefs about the malleability of sexual life is linked to higher levels of relationship satisfaction and sexual satisfaction and lower levels of problematic pornography use.

Personality and Individual Differences, 117, 15-22.

https://doi.org/10.1016/j.paid.2017.05.030

Bőthe, B., Tóth-Király, I., Zsila, Á., Griffiths, M. D., Demetrovics, Z., \& Orosz, G. (2018). The development of the Problematic Pornography Consumption Scale (PPCS). Journal of Sex Research, 55(3), 395-406. https://doi.org/10.1080/00224499.2017.1291798

Bőthe, B., Vaillancourt-Morel, M.-P., Bergeron, S., \& Demetrovics, Z. (2019). Problematic and non-problematic pornography use among LGBTQ adolescents: A systematic literature review. Current Addiction Reports. https://doi.org/10.1007/s40429-019-00289-5

Cooper, A. L. (1998). Sexuality and the internet: Surfing into the new millennium. Cyberpsychology and Behavior, 1(2), 187-193. https://doi.org/10.1089/cpb.1998.1.187 Cramer, A. O. J., \& Borsboom, D. (2015). Problems attract problems: A network perspective on 
mental disorders. In Emerging Trends in the Social and Behavioral Sciences (pp. 1-15). Hoboken, NJ, USA: John Wiley \& Sons, Inc. https://doi.org/10.1002/9781118900772.etrds0264

Crosby, J. M., \& Twohig, M. P. (2016). Acceptance and commitment therapy for problematic Internet pornography use: A randomized trial. Behavior Therapy, 47(3), 355-366. https://doi.org/10.1016/j.beth.2016.02.001

Dawson, K., Nic Gabhainn, S., \& MacNeela, P. (2019). Toward a model of porn literacy: Core concepts, rationales, and spproaches. Journal of Sex Research, 1-15. https://doi.org/10.1080/00224499.2018.1556238

Doornwaard, S. M., van den Eijnden, R. J. J. M., Overbeek, G., \& ter Bogt, T. F. M. (2015). Differential developmental profiles of adolescents using sexually explicit internet material. Journal of Sex Research, 52(3), 269-281. https://doi.org/10.1080/00224499.2013.866195

Efrati, Y., \& Gola, M. (2018). Understanding and predicting profiles of compulsive sexual behavior among adolescents. Journal of Behavioral Addictions, 7(4), 1004-1014. https://doi.org/10.1556/2006.7.2018.100

Epskamp, S., Borsboom, D., \& Fried, E. I. (2018). Estimating psychological networks and their accuracy: A tutorial paper. Behavior Research Methods, 50(1), 195-212. https://doi.org/10.3758/s13428-017-0862-1

Fernandez, D. P., \& Griffiths, M. D. (2019). Psychometric instruments for problematic pornography use: A systematic review. Evaluation \& the Health Professions. https://doi.org/10.1177/0163278719861688

Fried, E. I., van Borkulo, C. D., Cramer, A. O. J., Boschloo, L., Schoevers, R. A., \& Borsboom, D. (2017). Mental disorders as networks of problems: A review of recent insights. Social Psychiatry and Psychiatric Epidemiology, 52(1), 1-10. https://doi.org/10.1007/s00127-016- 
$1319-\mathrm{z}$

Griffiths, M. D. (2005). A “components" model of addiction within a biopsychosocial framework. Journal of Substance Use, 10(4), 191-197. https://doi.org/10.1080/14659890500114359

Griffiths, M. D. (2012, April). Internet sex addiction: A review of empirical research. Addiction Research and Theory. https://doi.org/10.3109/16066359.2011.588351

Grubbs, J. B., Kraus, S. W., \& Perry, S. L. (2019). Self-reported addiction to pornography in a nationally representative sample: the roles of use habits, religiousness, and moral incongruence. Journal of Behavioral Addictions, 8(1), 88-93. https://doi.org/10.1556/2006.7.2018.134

Grubbs, J. B., \& Perry, S. L. (2019). Moral incongruence and pornography use: A critical review and integration. Journal of Sex Research, 56(1), 29-37. https://doi.org/10.1080/00224499.2018.1427204

Hald, G. M. (2006). Gender Differences in Pornography Consumption among Young Heterosexual Danish Adults. Archives of Sexual Behavior, 35(5), 577-585. https://doi.org/10.1007/s10508-006-9064-0

Harper, C., \& Hodgins, D. C. (2016). Examining correlates of problematic Internet pornography use among university students. Journal of Behavioral Addictions, 5(2), 179-191. https://doi.org/10.1556/2006.5.2016.022

Hayes, S. C., Luoma, J. B., Bond, F. W., Masuda, A., \& Lillis, J. (2006). Acceptance and Commitment Therapy: Model, processes and outcomes. Behaviour Research and Therapy, 44(1), 1-25. https://doi.org/10.1016/j.brat.2005.06.006

Hevey, D. (2018). Network analysis: A brief overview and tutorial. Health Psychology and Behavioral Medicine, 6(1), 301-328. https://doi.org/10.1080/21642850.2018.1521283 
Hox, J. J. (2010). Multilevel Analysis: Techniques and Applications (2nd ed.). New York, NY: Routledge.

JASP Team. (2019). JASP (Version 0.10) Computer Software.

Jung, T., \& Wickrama, K. A. S. (2008). An Introduction to Latent Class Growth Analysis and Growth Mixture Modeling. Social and Personality Psychology Compass, 2(1), 302-317. https://doi.org/10.1111/j.1751-9004.2007.00054.x

Keen, C., France, A., \& Kramer, R. (2019). Exposing children to pornography: How competing constructions of childhood shape state regulation of online pornographic material. $\mathrm{New}$ Media \& Society, 12(5), 146144481987253. https://doi.org/10.1177/1461444819872539

Kohut, T. (2014). An Empirical Investigation Of The Concept Of "Pornography." Electronic Thesis and Dissertation Repository. Retrieved from https://ir.lib.uwo.ca/etd/2063

Kohut, T., \& Štulhofer, A. (2018a). Is pornography use a risk for adolescent wellbeing? An examination of temporal relationships in two independent panel samples. PLoS ONE, 13(8). https://doi.org/10.1371/journal.pone.0202048

Kohut, T., \& Štulhofer, A. (2018b). The role of religiosity in adolescents' compulsive pornography use: A longitudinal assessment. Journal of Sex \& Marital Therapy, 44(8), 759775. https://doi.org/10.1080/0092623X.2018.1466012

Kolesarić, V., \& Ajduković, M. (Eds.). (2003). Etički kodeks istraživanja s djecom (Ethical Guidelines for Research in Minors). Zagreb: Vijeće za djecu Vlade Republike Hrvatske.

Kor, A., Zilcha-Mano, S., Fogel, Y. A., Mikulincer, M., Reid, R. C., \& Potenza, M. N. (2014). Psychometric development of the Problematic Pornography Use Scale. Addictive Behaviors, 39(5), 861-868. https://doi.org/10.1016/j.addbeh.2014.01.027

Kraus, S. W., Krueger, R. B., Briken, P., First, M. B., Stein, D. J., Kaplan, M. S., .. Reed, G. M. (2018). Compulsive sexual behaviour disorder in the ICD-11. World Psychiatry, 17(1), 109- 
110. https://doi.org/10.1002/wps.20499

Kvalem, I. L., Træen, B., Lewin, B., \& Štulhofer, A. (2014). Self-perceived effects of internet pornography use, Genital appearance satisfaction, And sexual self-esteem among young scandinavian adults. Cyberpsychology, 8(4). https://doi.org/10.5817/CP2014-4-4

Laili, M. M., Puspitawati, H., \& Yuliati, L. N. (2018). Is it parental communication, self-esteem, or Internet use that makes pornography behavior in teenagers? (cases of pornography and porno-action). Journal of Child Development Studies, 3(1), 59. https://doi.org/10.29244/jcds.3.1.59-69

Lo, V. H., \& Wei, R. (2005). Exposure to Internet pornography and Taiwanese adolescents' sexual attitudes and behavior. Journal of Broadcasting \& Electronic Media, 49(2), 221-237. https://doi.org/10.1207/s15506878jobem4902_5

Marinović Jerolimov, D., \& Jokić, B. (2010). Religion and Youth in Croatia. In G. Giordan (Ed.), Annual Review of the Sociology of Religion, Volume 1: Youth and Religion. Leiden: Brill.

Mitchell, K. J., \& Wells, M. (2007). Problematic Internet experiences: Primary or secondary presenting problems in persons seeking mental health care? Social Science and Medicine, 65(6), 1136-1141. https://doi.org/10.1016/j.socscimed.2007.05.015

Muthén, L. K., \& Muthén, B. O. (2017). Mplus User's Guide (8th ed.). Los Angeles, CA: Muthen \& Muthen.

Noor, S. W., Rosser, B. R. S., \& Erickson, D. J. (2014a). A brief scale to measure problematic sexually explicit media consumption: psychometric properties of the Compulsive Pornography Consumption (CPC) Scale among men who have sex with men. Sexual Addiction \& Compulsivity, 21(3), 240-261. https://doi.org/10.1080/10720162.2014.938849

Noor, S. W., Rosser, B. R. S., \& Erickson, D. J. (2014b). A Brief Scale to Measure Problematic Sexually Explicit Media Consumption: Psychometric Properties of the Compulsive 
Pornography Consumption (CPC) Scale Among Men Who Have Sex With Men. Sexual Addiction \& Compulsivity, 21(3), 240-261. https://doi.org/10.1080/10720162.2014.938849

Nuijten, M. B., Deserno, M. K., Cramer, A. O. J., \& Borsboom, D. (2016). Mental disorders as complex networks: An introduction and overview of a network approach to psychopathology. Clinical Neuropsychiatry, 13(4/5), 68-76.

Oberski, D. (2016). Mixture models: Latent profile and latent class analysis. In J. Robertson \& M. Kaptein (Eds.), Modern Statistical Methods for HCI. Human-Computer Interaction Series. Cham: Springer.

Owens, E. W., Behun, R. J., Manning, J. C., \& Reid, R. C. (2012). The impact of Internet pornography on adolescents: A review of the research. Sexual Addiction \& Compulsivity, 19(1-2), 99-122. https://doi.org/10.1080/10720162.2012.660431

Paul, B., \& Shim, J. W. (2008). Gender, sexual affect, and motivations for internet pornography use. International Journal of Sexual Health, 20(3), 187-199. https://doi.org/10.1080/19317610802240154

Peter, J., \& Valkenburg, P. M. (2016). Adolescents and pornography: A review of 20 years of research. Journal of Sex Research, 53(4-5), 509-531. https://doi.org/10.1080/00224499.2016.1143441

Peugh, J. L. (2010). A practical guide to multilevel modeling. Journal of School Psychology, 48(1), 85-112. https://doi.org/10.1016/j.jsp.2009.09.002

Pizzol, D., Bertoldo, A., \& Foresta, C. (2016). Adolescents and web porn: A new era of sexuality. International Journal of Adolescent Medicine and Health, 28(2), 169-173. https://doi.org/10.1515/ijamh-2015-0003

Rissel, C., Richters, J., de Visser, R. O., McKee, A., Yeung, A., \& Caruana, T. (2017a). A profile of pornography users in Australia: Findings from the second Australian Study of Health and 
Relationships. Journal of Sex Research, 54(2), 227-240.

https://doi.org/10.1080/00224499.2016.1191597

Rissel, C., Richters, J., de Visser, R. O., McKee, A., Yeung, A., \& Caruana, T. (2017b). A Profile of Pornography Users in Australia: Findings From the Second Australian Study of Health and Relationships. Journal of Sex Research, 54(2), 227-240.

https://doi.org/10.1080/00224499.2016.1191597

Ross, M. W., Månsson, S.-A., \& Daneback, K. (2012). Prevalence, Severity, and Correlates of Problematic Sexual Internet Use in Swedish Men and Women. Archives of Sexual Behavior, 41(2), 459-466. https://doi.org/10.1007/s10508-011-9762-0

Sniewski, L., Farvid, P., \& Carter, P. (2018, February 1). The assessment and treatment of adult heterosexual men with self-perceived problematic pornography use: A review. Addictive Behaviors. Elsevier Ltd. https://doi.org/10.1016/j.addbeh.2017.10.010

Štulhofer, A., Tafro, A., \& Kohut, T. (2019). The dynamics of adolescents' pornography use and psychological well-being: A six-wave latent growth and latent class modeling approach. European Child \& Adolescent Psychiatry. https://doi.org/10.1007/s00787-019-01318-4

Svedin, C. G., Akerman, I., \& Priebe, G. (2011). Frequent users of pornography. A population based epidemiological study of Swedish male adolescents. Journal of Adolescence, 34(4), 779-788. https://doi.org/10.1016/j.adolescence.2010.04.010

the jamovi project. (2019). jamovi. (Version 1.0). Retrieved from https://www.jamovi.org. Tomić, I., Burić, J., \& Štulhofer, A. (2018). Associations Between Croatian Adolescents’ Use of Sexually Explicit Material and Sexual Behavior: Does Parental Monitoring Play a Role? Archives of Sexual Behavior, 47(6), 1881-1893. https://doi.org/10.1007/s10508-017-1097-z Tomyn, A. J., \& Cummins, R. A. (2011). The subjective wellbeing of high-school students: Validating the Personal Wellbeing Index-School Children. Social Indicators Research, 
101(3), 405-418. https://doi.org/10.1007/s11205-010-9668-6

Twohig, M. P., \& Crosby, J. M. (2010). Acceptance and Commitment Therapy as a treatment for problematic Internet pornography viewing. Behavior Therapy, 41(3), 285-295. https://doi.org/10.1016/j.beth.2009.06.002

Vaillancourt-Morel, M.-P., Blais-Lecours, S., Labadie, C., Bergeron, S., Sabourin, S., \& Godbout, N. (2016). Profiles of cyberpornography use and sexual well-being in adults. Journal of Sexual Medicine, 14(1), 78-85. https://doi.org/10.1016/j.jsxm.2016.10.016 Van Borkulo, C., Waldorp, L. J., Boschloo, L., Kossakowski, J., Tio, P., Schoevers, R. A., \& Borsboom, D. (2016). Comparing network structures on three aspects: A permutation test. Submitted. https://doi.org/10.13140/RG.2.2.29455.38569

Vandenbosch, L., \& van Oosten, J. M. F. (2017). The relationship between online pornography and the sexual objectification of women: The attenuating role of porn literacy education. Journal of Communication, 67(6), 1015-1036. https://doi.org/10.1111/jcom.12341

Werner, M., Štulhofer, A., Waldorp, L., \& Jurin, T. (2018). A network approach to hypersexuality: Insights and clinical implications. Journal of Sexual Medicine, 15(3), 410415. https://doi.org/10.1016/j.jsxm.2018.01.009

Wery, A., \& Billieux, J. (2017). Problematic cybersex: Conceptualization, assessment, and treatment. Addictive Behaviors, 64, 238-246. https://doi.org/10.1016/j.addbeh.2015.11.007

Williams, G. A., \& Kibowski, F. (2016). Latent class analysis and latent profile analysis. In L. A. Jason \& D. S. Glenwick (Eds.), Handbook of Methodological Approaches to CommunityBased Research: Qualitative, Quantitative, and Mixed Methods (pp. 143-152). Oxford: Oxford University Press. https://doi.org/10.1093/med:psych/9780190243654.003.0015 Willoughby, B. J., Young-Petersen, B., \& Leonhardt, N. D. (2018). Exploring trajectories of pornography use through adolescence and emerging adulthood. Journal of Sex Research, 
55(3), 297-309. https://doi.org/10.1080/00224499.2017.1368977 
Figure 1 - Structure of Problematic Pornography Use at Two Time Points, 6 Months Apart


Legend:

Item $1=$ I thought of pornography when I was trying to focus on other things

Item 2 = I was upset because I could not stop thinking about pornography.

Item 3 = I watched pornography even though I did not want to.

Item $4=$ It was necessary for me to watch pornography to feel at ease.

Item 5 = I could only an orgasm when watching pornography.

Note. Network structure at $\mathrm{T} 5$ is presented on the left and network structure at T6, expressed as difference scores, on the right. 
Figure 2 - Item Centrality Indices in the Network of Problematic Pornography Use at T5 and T6



Item $1=$ I thought of pornography when I was trying to focus on other things.

Item 2 = I was upset because I could not stop thinking about pornography.

Item 3 = I watched pornography even though I did not want to.

Item $4=$ It was necessary for me to watch pornography to feel at ease.

Item 5 = I could only an orgasm when watching pornography. 
Figure 4 - Latent Profiles of Problematic Pornography Use at T5 (Top Graph) and T6 (Bottom Graph)
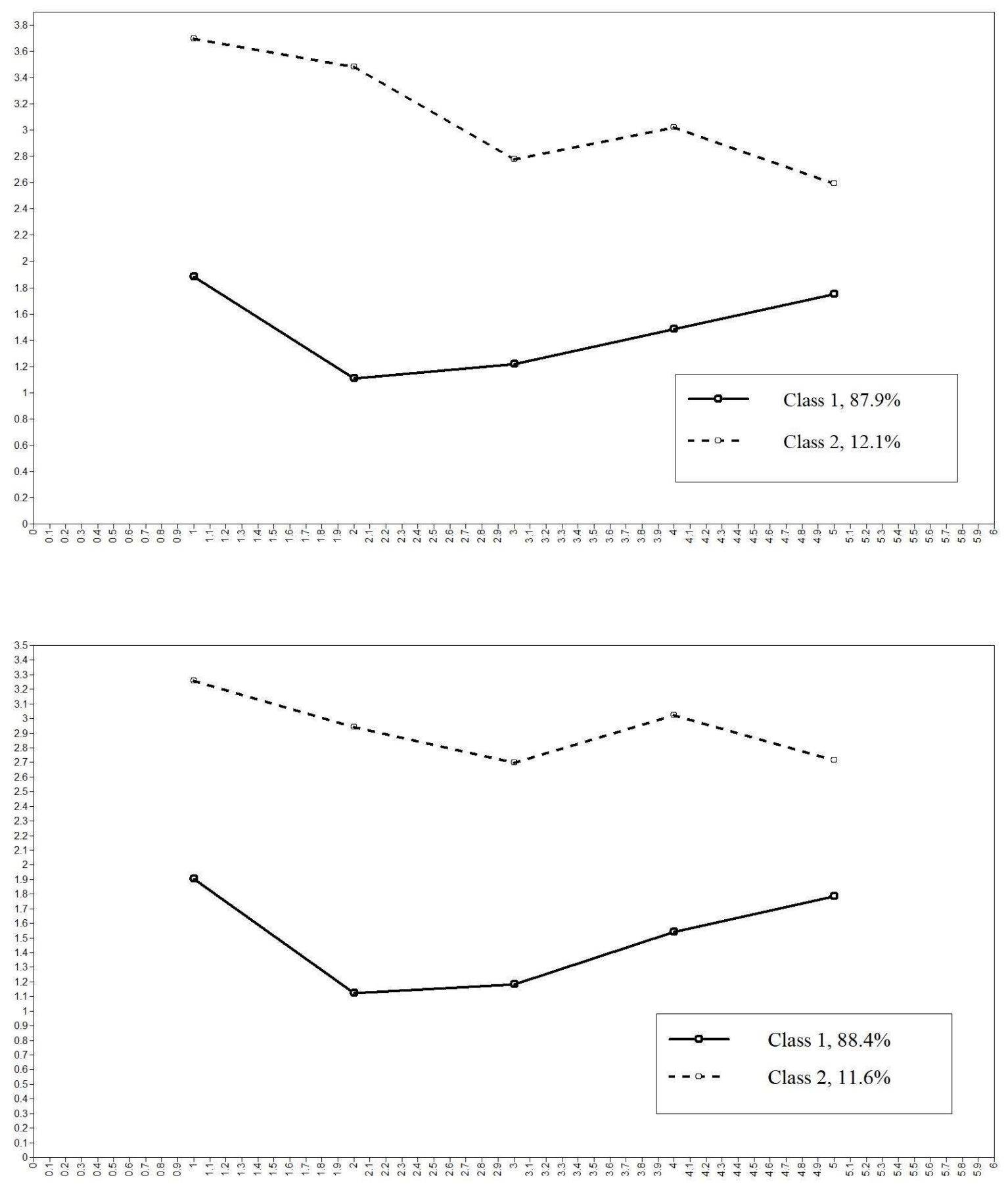
Table 1 - Linear Mixed Effects Regression Analysis of the Associations between Sexual and Life Satisfaction, and Problematic Pornography Use in Male Croatian Adolescents Across a 6-Month Period

\begin{tabular}{|c|c|c|c|c|c|c|c|}
\hline & \multirow[b]{2}{*}{$b$} & \multirow[b]{2}{*}{$\mathrm{SE}$} & \multicolumn{2}{|c|}{$\begin{array}{c}95 \% \text { Confidence } \\
\text { Interval }\end{array}$} & \multirow[b]{2}{*}{$\mathrm{df}$} & \multirow[b]{2}{*}{$t$} & \multirow[b]{2}{*}{$p$} \\
\hline & & & Lower & Upper & & & \\
\hline (Intercept) & 8.14 & 0.21 & 7.74 & 8.55 & 29.5 & 39.45 & $<.001$ \\
\hline Sexual satisfaction $^{\mathrm{a}}$ & -0.15 & 0.10 & -0.36 & 0.04 & 448.9 & -1.53 & 0.126 \\
\hline $\begin{array}{l}\text { Life satisfaction (at } \\
\text { T6) }\end{array}$ & -0.14 & 0.05 & -0.24 & -0.04 & 436.1 & -2.74 & 0.006 \\
\hline Participant's age & -0.20 & 0.33 & -0.84 & 0.45 & 449.0 & -0.60 & 0.548 \\
\hline
\end{tabular}

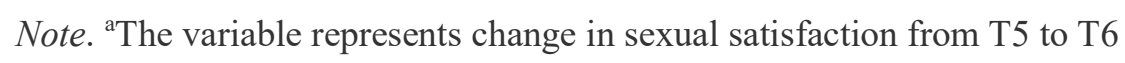


Table 2 - Classification Fit Parameters for LPA of Problematic Pornography Use at T5 and T6

\begin{tabular}{|c|c|c|}
\hline & T5 & T6 \\
\hline & AIC; BIC; SABIC; entropy & AIC, BIC, SABIC, entropy \\
\hline 1-profile model & 3719; 3755; 3723; n. a. & 4549; 4588; 4556; n. a. \\
\hline 2-profile model & $3194 ; 3251 ; 3200 ; .995$ & $4069 ; 4130 ; 4080 ; .967$ \\
\hline 3-profile model & $3030 ; 3108 ; 3039 ; .998$ & $3940 ; 4024 ; 3954 ; .926$ \\
\hline 4-profile model & $2941 ; 3041 ; 2952 ; .960$ & $3860 ; 3967 ; 3878 ; .867$ \\
\hline
\end{tabular}

